\title{
AGRICULTURAL LAND CHANGE DETECTING AND FORECASTING USING COMBINATION OF FEEDFORWARD MULTILAYER NEURAL NETWORK, CELLULAR AUTOMATA AND MARKOV CHAIN MODELS
}

\author{
A. Babaeian Diva ${ }^{1}$, B. Bigdeli ${ }^{2, *}$, P. Pahlavani ${ }^{1}$ \\ ${ }^{1}$ School of Surveying and Geospatial Engineering, College of Engineering, University of Tehran, Tehran, Iran - (ali.babaeian, \\ pahlavani@ut.ac.ir) \\ ${ }^{2}$ School of Civil Engineering, Shahrood University of Technology, Shahrood, Iran - bigdeli@ shahroodut.ac.ir
}

KEY WORDS: Markov Chain, Cellular automata, Land use/cover change Prediction, Feedforward multilayer neural network

\begin{abstract}
:
This paper proposed a methodology for finding changes in agricultural land of Tehran during past years and simulating these changes for future years. The proposed method utilized the spatial GIS-based techniques and Landsat satellite imagery to predict agricultural land map for the future of Tehran. Therefore, a method for finding and predicting changes based on combining the feedforward multilayer perceptron neural network (MLP), cellular automata (CA), and Markov chain model were applied. In this regard, the Landsat images of 2002, 2008, and 2014 were classified by a binary support vector machine classifier into two classes of agricultural and nonagricultural. Then, the potential transition maps were generated by the neural network MLP and extensible areas were obtained by the Markov chain model. Finally, the results of these two steps were combined with the MOLA method and the 2020 and 2025 agricultural maps were predicted. The proposed method obtained the Kappa factor of $89.92 \%$ that indicates the high ability of the neural network and the CA-Markov for finding the changes and prediction in the city of Tehran.
\end{abstract}

\section{INTRODUCTION}

Land use change is a very important issue in the natural world that has a great impact on the environment. The living standards of humans and other creatures of Human activities, especially economic activities, are the main drivers of land use changes. Therefore, understanding the status and process of regional land use change is crucial for the sustainable development of the region (Fan, Wang, \& Wang, 2008). Land is one of the primary natural resources that changes over time. Land use changes is a natural process and cannot be stopped but can be controlled. Land use changes are very important in urban management decisions and urban planning. In some countries agricultural lands turns to non-agricultural with the growth of the population and the economy. In recent decades, the result of this process provided extensive changes in the land use and environmental issues such as destruction, erosion and pollution of soil, water and air. Agriculture is vital for people because it is a source of food, income and social rights (Rudel et al., 2005). Therefore, ensuring access to agriculture, reduces vulnerability to hunger and poverty.

In this research, we intend to investigate the impact of urban growth of Tehran - as a capital of Iran and a mega city - on 'agricultural' land use change, predicting the trend of change, and determining agricultural areas in terms of risk of conversion to the 'building' land use.

Recent notable advances in data and technology integration between remote sensing and GIS are known as a powerful and effective tools in urban studies (Bigdeli et al., 2013; Bigdeli et al., 2014). However, GIS provides a powerful capability to import, analyze and display digital data from a variety of sources and formats (Delavar, 2004; Pahlavani et al., 2006; Pahlavani et al., 2017; Bahari et al., 2014). Considerable research has been done using remote sensing and GIS for urban growth.
The land use changes can be modeled using various methods such as Cellular Automata CA(X. Li \& Yeh, 2010; Tripathy \& Kumar, 2019), artificial neural network ANN based models (Dadhich \& Hanaoka, 2010; Islam, Rahman, \& Jashimuddin, 2018), regression based models (Xia, Zhang, Wang, \& Yeh, 2019; Mathur, 2019), Agent Based AB models (Jokar, Helbich, \& Noronha, 2013; Aarthi \& Gnanappazham, 2018), and combined methods. This paper tries to investigate and develop a method for modelling and predicting agricultural land changes for the future by a multilayer perceptron neural network (MLP), Markov chain, and cellular automata (CA).

\section{STUDY AREA}

The study area of this research is Tehran, capital of Iran (Figure 1). Tehran is located in the north of the country and south of the Alborz mountain range. The city's economic and political conditions caused excessive influx of population and migration in recent years, which has led to the expansion of the urban area. Because of the challenges in urban planning and management, a model for this city has been implemented. The city is located between $51^{\circ} 06^{\prime} \mathrm{E}$ to $51^{\circ} 38^{\prime} \mathrm{E}$ longitude and $35^{\circ} 34^{\prime} \mathrm{N}$ to $35^{\circ} 51^{\prime} \mathrm{N}$ latitudes.

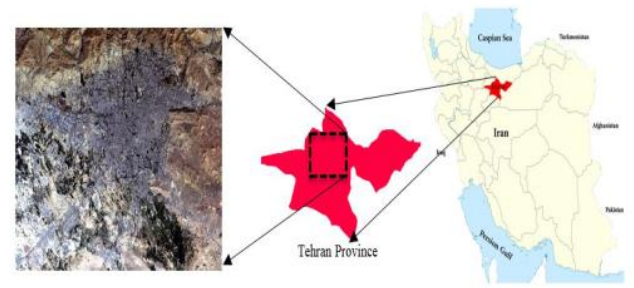

Figure 1. Study area, Tehran, Iran

3. DATA AND INDEPENDENT FACTORS

Table 1 illustrates information of Tehran data.

\footnotetext{
* Corresponding author
} 


\begin{tabular}{|c|c|c|}
\hline raster & 200220082014 & Landsat images \\
\hline vector & 200220082014 & roads of Tehran \\
\hline raster & 2008 & Digital elevation model \\
\hline vector & 200220082014 & river \\
\hline vector & 200220082014 & population \\
\hline vector & 200220082014 & Map of the villages of Tehran \\
\hline
\end{tabular}

Table 1. Initial data for Tehran city

Independent factors considered as inputs to the neural network all of these parameters are normalized to between 0 and 1 . It was then converted to a pixel image equal to the pixels of the user maps. These parameters each pixel have a value that is a pixel value. All parameters were generated using Spatial Analyze tool in ArcGIS software. the independent factors used in the paper are Digital elevation model, slope, distance to residential areas, population, distance to green space, distance to agriculture, distance to wasteland, distance to dense urban areas, distance to river, distance to roads, distance to villages, regional military, agricultural, residential, green space and wasteland. Figure 2 shows some examples of these factors.

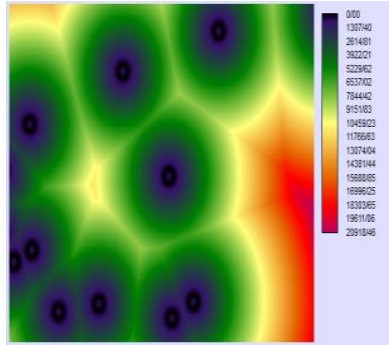

(a)

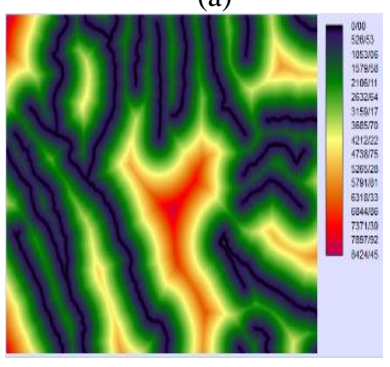

(c)

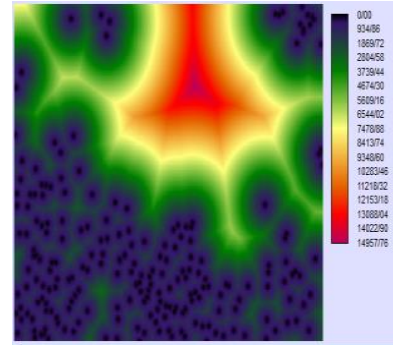

(b)

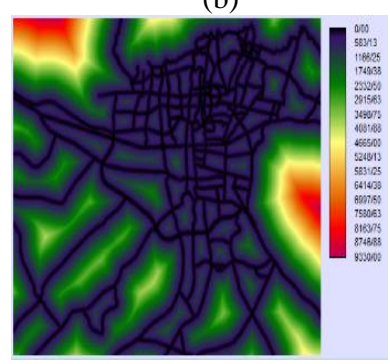

(d)
Figure 2. Some independent factors for 2002; (a) Distance to nearby cities, (b) Village, (c) rivers, (d) roads

\section{PROPOSED METHOD AND EXPERIMENTAL RESULTS}

Figure 3 shows the flowchart of the proposed method.

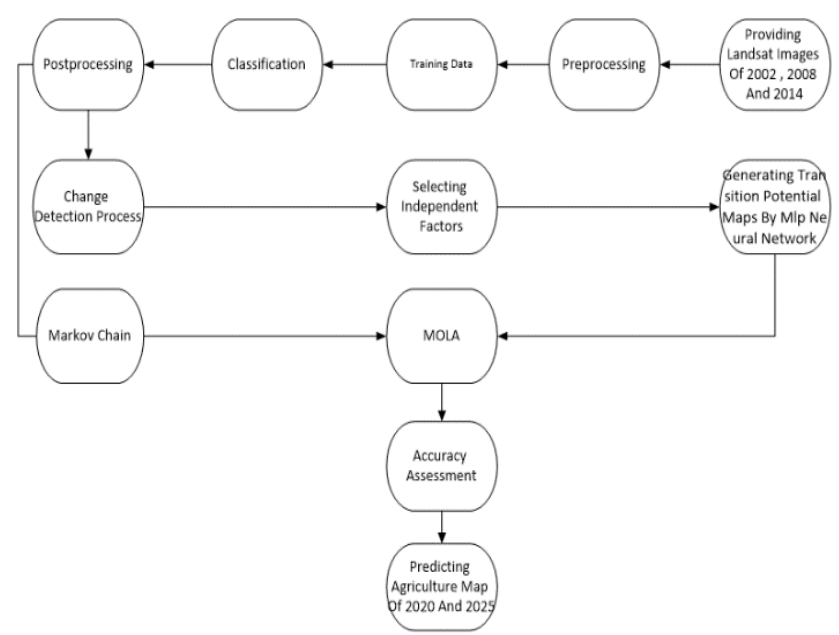

Figure 3. Flowchart of the proposed method

Support Vector Machine (SVM) classification is based on the theory of statistical learning and aims to determine the boundaries of decision making that optimize the separation of classes (Saitta, 1995). On the problem of identifying a two-class pattern in which the classes are linearly separated, the SVM selects between an infinite set of linear decision boundaries that minimizes the generalization error. Therefore, the boundary of the chosen decision will be the one that leaves the most margin between the two classes, where margin is defined as the sum of the distances to the hyperplane from the closest points of the two classes (Saitta, 1995).

In this research, Landsat (TM) satellite image of 2002, Landsat (TM) image of 2008, and Landsat (ETM +) image of 2014 of Tehran were applied in classification section. At first, the radiometric and atmospheric corrections and pre-processing were applied on all data. After selection of training data, a binary SVM classification method (agricultural and non-agricultural classes) was utilized for classification of three Landsat images. The obtained overall accuracies for 2002, 2008, and 2014 images were $93.65 \%, 94.17 \%$, and $94.83 \%$, respectively. Figure 4 shows the classified land use map for these years.

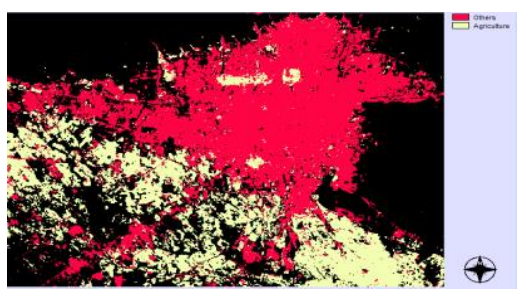

(a)

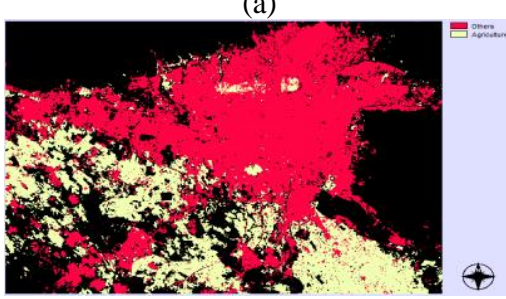

(b)

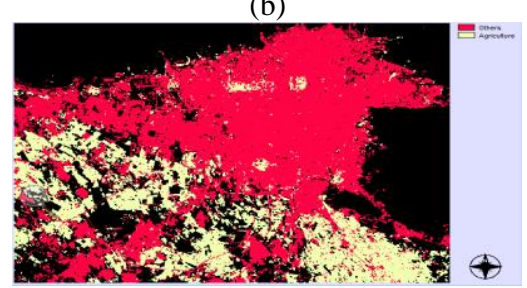


(c)

Figure 4 . The classified land use maps for (a) 2002, (b) 2008, (c) 2014 Landsat

images

The neural network contains one input layer and one or multiple middle layers and one output layer (Figure 5). Different types of neural networks exist depending on the type of connection between neurons. The type of network learning algorithm and the type of stimulus function are different. The feedforward multilayer perceptron neural network (MLP) consists of a number of neurons which link the input set to the output. The advantages of this method are its high accuracy and ability to solve (non)linear problems with no sensitivity to noise and error in statistical data. In this type of neural networks, the input vector is applied to the input neurons and its effects propagate through the hidden layer to the output layer. When the values are weighted by the stimulation functions $f$ they take the true value of the output of the neuron (Lin, Lu, Espey, \& Allen, 2005).

Relationships represent the relationship between different layers(Pijanowski, Brown, Shellito, \& Manik, 2002):

$$
\begin{aligned}
O_{j} & =f\left(\sum_{i} O_{i} W_{i j}-b_{j}\right) \\
O_{k} & =f\left(\sum_{j} O_{j} W_{j k}-b_{k}\right)
\end{aligned}
$$

where $\quad W_{i j}$ is weight between the neuron $i$ of the input layer and the neuron $j$ of the hidden layer,

$W_{j k}$ is weight between the neuron $j$ of the hidden layer and the neuron $k$ of the output layer,

$b$ is bias,

$f$ is transfer function,

$O_{k}, O_{j}, O_{i}=$ represent the input, hidden, and output layer neurons, respectively.

In this study, the sigmoid hyperbolic tangent function and the linear function were used to transfer between input-hidden and hidden-output layers, respectively(Pijanowski et al., 2002):

$$
\begin{gathered}
f(x)=\frac{2}{1+e^{-2 x}}-1 \\
f(x)=x
\end{gathered}
$$

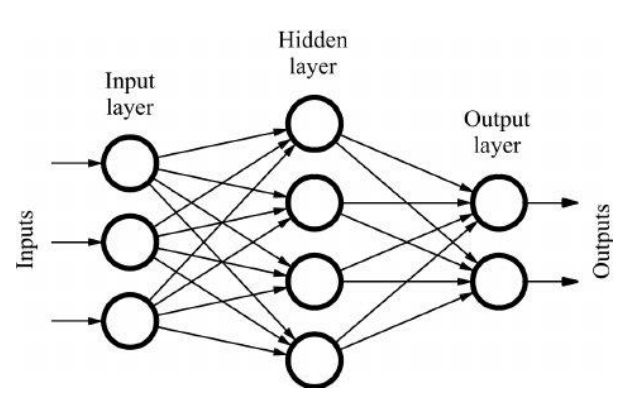

Figure 5. An example of a three-layer artificial neural network structure

In the path of departure after identifying the input vector for each neuron, a weight is randomly assigned and the stimulation functions are applied to each neuron of each layer. Along the way, the parameters of the relationships remain constant in the return path, the network parameters are changed and adjusted. Along this path, changes are made based on the error vector by comparing the network output and the actual value for each training data(Xiao et al., 2006).

$$
e_{j}(k)=t_{i}(k)-o_{i}(k)
$$

where $\quad t=$ Expected amount

$\mathrm{o}=$ Network output value

$\mathrm{e}=$ Moment error for each neuron in $\mathrm{k}$ cycle $\mathrm{b}=$ bias

$\mathrm{f}=$ Transfer function

$\mathrm{e}=$ Moment error for each neuron in $\mathrm{k}$ cycle

The network error is calculated as (Almeida, Gleriani, Castejon, \& Soares-Filho, 2008):

$$
\begin{gathered}
R M S E=\sqrt{\frac{\sum_{i=1}^{n}\left(t_{i}(k)-o_{i}(k)\right)^{2}}{n}} \\
W_{n}(k+1)=W_{n}(k)-a \times \Delta W_{n}(k) \\
b_{n}(k+1)=b_{n}(k)-a \times \Delta b_{n}(k) \\
\Delta W_{n}(k)=\frac{\partial F(k)}{\partial W_{n}(k)} \\
\Delta b_{n}(k)=\frac{\partial F(k)}{\partial b_{n}(k)}
\end{gathered}
$$

where $n$ is number of training data in the network error returning path and weights and bias are reset by Eqs. (9) and (10), and

$a$ is a learning rate.

After classification step, transition potential map was created by the feedforward multilayer neural network with 16 input layer neurons, 6 hidden layer neurons and 2 output layer neurons (Table 2 and Figure 5).

\begin{tabular}{|c|c|}
\hline Input layer neurons & 16 \\
\hline Hidden layer neurons & 6 \\
\hline Output layer neurons & 2 \\
\hline Requested samples per class & 4500 \\
\hline Final learning rate & 0.0003 \\
\hline Momentum factor & 0.5 \\
\hline Sigmoid constant & 1 \\
\hline Acceptable RMS & 0.01 \\
\hline Iterations & 30000 \\
\hline Training RMS & 0.2507 \\
\hline Testing RMS & 0.2700 \\
\hline Accuracy rate & $91.17 \%$ \\
\hline Skill measure & 0.8234 \\
\hline
\end{tabular}

Table 1. The MLP parameters and results

The Cramer's coefficients, which show the relationship between independent factors and land use class, were calculated and the coefficients of two factors, i.e. Aspect and Ground fault, were 0.00008 and 0.00004 , and were removed from the independent factors. 


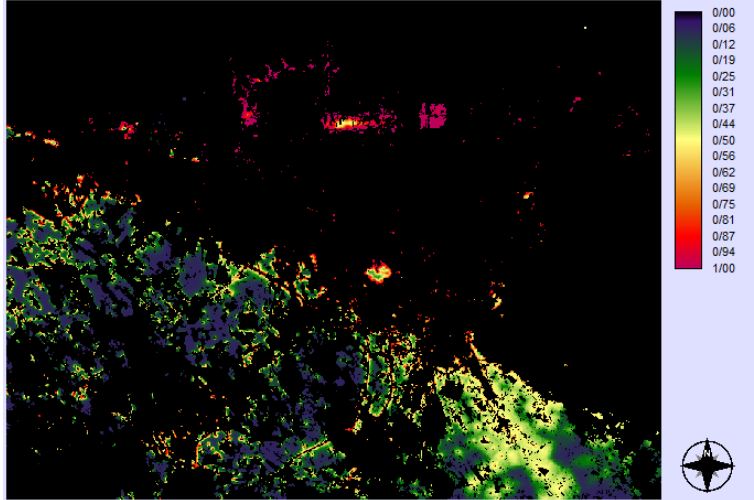

Figure 6. Transition potential map

Transition potential map is actually a map whose pixel values are between 0 and 1 . The higher the value indicates that the pixel is more likely to change the user.

Markov chain is a model that expresses the probability of changing from one state at time $t_{1}$ to another at time $t_{2}$ using the transfer matrix.

The main feature of this method is that the next activity depends only on the current activity and it does not depend on the past activities and neighbours (Muller \& Middleton, 1994; Huang, Wu, Gao, Zhan, \& Cui, 2015) .

The Markov chain is composed of three matrices $M_{t}$ and $M_{t+1}$ transition matrices, which are the number of pixels per user at time $t$ and $t+1$ :

$$
\begin{gathered}
M_{L C} \times M_{t}=M_{t+1} \\
{\left[\begin{array}{ll}
L C_{F F} & L C_{F B} \\
L C_{B F} & L C_{B B}
\end{array}\right] \times\left[\begin{array}{c}
F_{t} \\
B_{t}
\end{array}\right]=\left[\begin{array}{l}
F_{t+1} \\
B_{t+1}
\end{array}\right]}
\end{gathered}
$$

where $F$ is agricultural land use,

$B$ is non-agricultural land use,

$L C_{B F}$ is probability of change from user $b$ at time $t$ to user $f$ at time $(t+1)$,

$F_{t} \cdot B_{t}$ is the number of pixels in the user $F, B$.

The transmission probability matrix shows the possibility of transferring any of the land use to another. Transition area matrix records the number of cells expected to change from one type of land cover to another over the next period. The weakness of the Markov chain is to determine the spatial distribution of land use changes that we use for cellular automata to resolve this problem. If the Markov chain model contains a sequence of random variables $x_{1}, x_{2}, x_{3}, x_{n}$; this means that if a set of conditions have to be $S=\left\{s_{1} \cdot s_{2} \cdot s_{3} \ldots . s_{r}\right\}$ then $p_{i j}$ is calculated by:

$$
p_{i j}^{(n)}=\sum_{k=1}^{r} p_{i k} p_{k j}
$$

Cellular automata are an array of interconnected members in which computation is performed in parallel and simultaneously with local communications(Batty \& Xie, 1994). This computational model was first introduced by Von Neumann. Cellular automatons are components that are adjacent to each other, and the behaviour of these components is defined based on the behaviour of the neighbours and their own and neighbours' experiences.

A CA-Markov is a powerful approach in spatial and temporal dynamic modelling for land use changes (H. Li \& Reynolds, 1997; Kamusoko, Aniya, Adi, \& Manjoro, 2009).
This method with the number of expandable pixels predicted by the Markov method and competency maps identifies the pixels susceptible to expansion at the $n$ interval desired to predict each step and overlaps with the map at the beginning of the interval and eventually the desired map is predicted.

To predict the transition area for each land use, the Markov chain method was developed using the behavior of land use change between 2002 and 2008. Also the MOLA method uses the concept of the minimum distance to the ideal pixel. Agricultural Potential Transition are introduced to MOLA for prediction of the agricultural changes map for 2020 and 2025 (Figure 10).

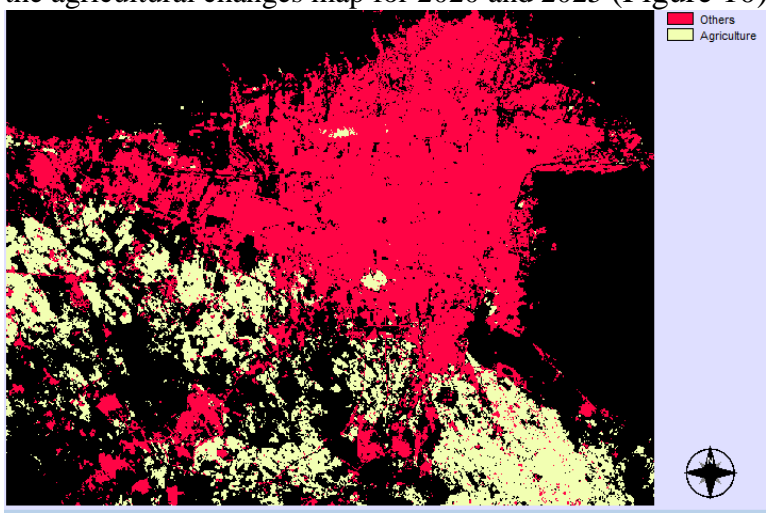

Figure 7. The predicted land use map of 2014

The results of the neural network show $91.17 \%$ accuracy for change extraction. The average of training and testing RMSE were 0.2507 and 0.2700 (Figure 8 ) respectively. The results of the RMSEs indicate the high ability and accuracy of neural network for modelling of agriculture. To validate the model, simulated land use map in 2014 was compared with the actual of classified satellite image of the same year. The calculated Kappa coefficient was $89.92 \%$ that indicates the high capacity of the neural network and CA-Markov for simulation of agricultural changes in Tehran.

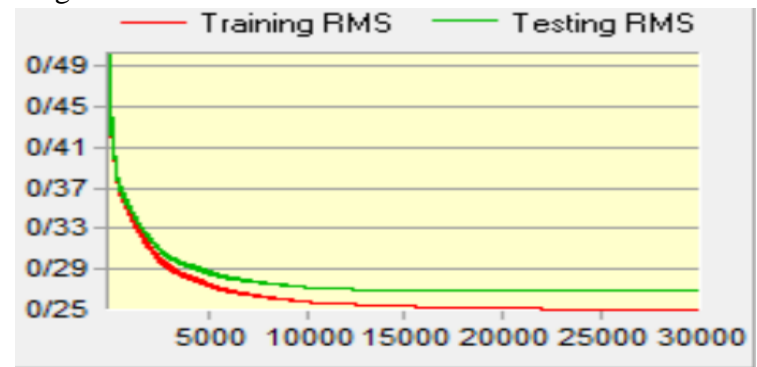

Figure 8. The average of training and testing RMSE

\section{CONCLUSION}

In 6 years, 1740 hectares of agricultural lands have been changed and 603 hectares have been added to the area of agricultural land as shown in Figure 6. In total, 1137 hectares were lost as shown in Figure 7.

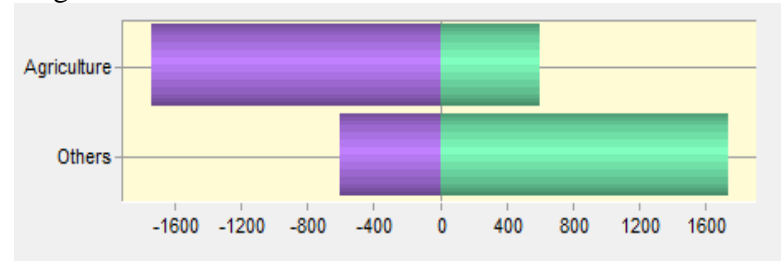

(a) 


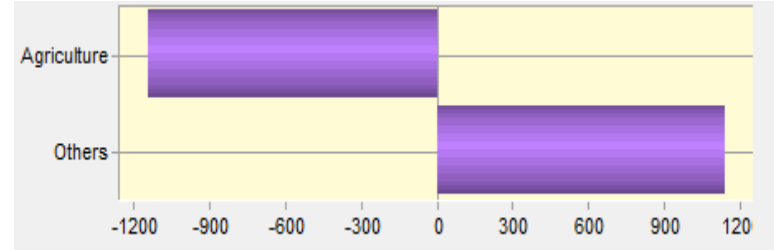

(b)

Figure 9. (a) Gain and lose graph, (b) Net change graph

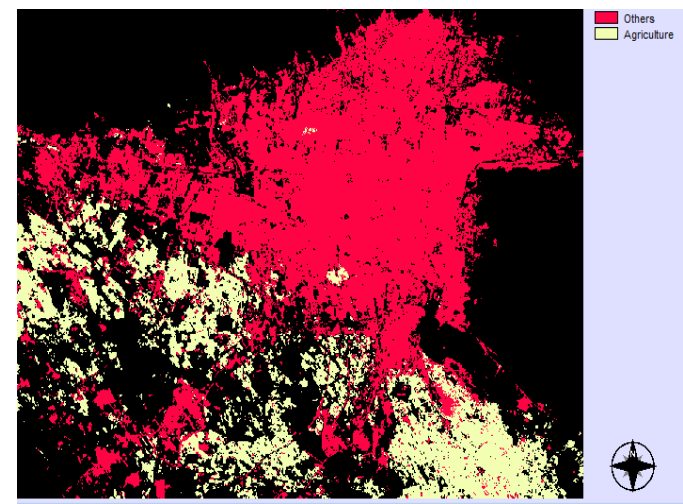

(a)

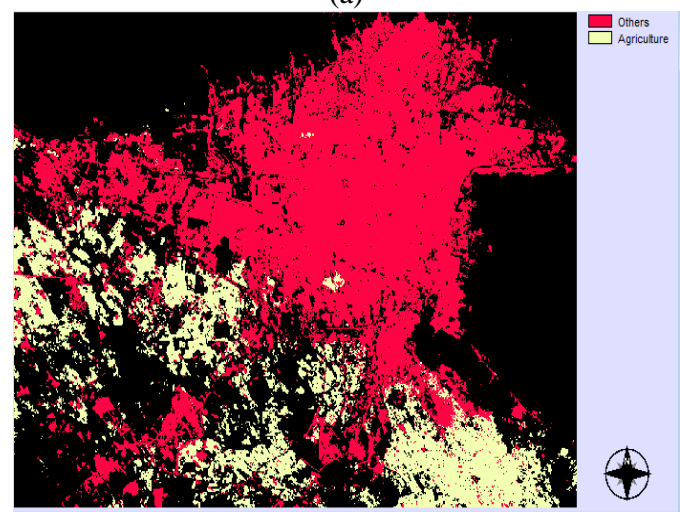

(b)

Figure 10. The predicted land use map of (a) 2020, and (b) 2025

Trend changes show that land prices have been very effective in changing land use in the north of Tehran where agricultural land use changed to residential land use.

Areas that had the largest increase in agricultural land use were generally in southwest of Tehran and the agricultural lands in northern Tehran were either dried up or changed during the period 2002-2008(Figure 11)

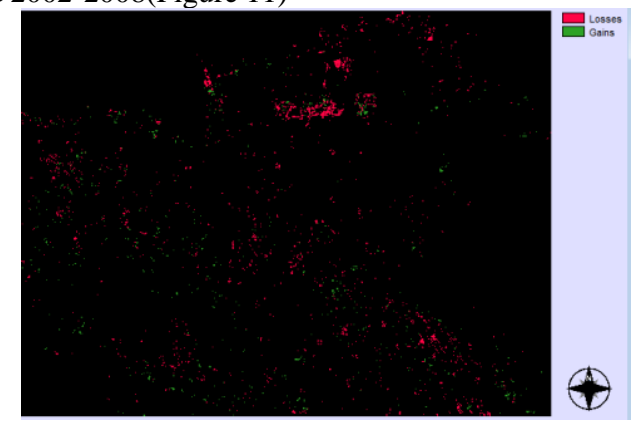

Figure 11. Agriculture land use change map during the period 2002-2008

Map of the probability of reducing agricultural land for the future from comparison of prediction map for 2020 with the actual map for 2014, shows that a large area of agricultural land is being demolished and needs special care, proper protection, and policy decisions. (Figure 12)

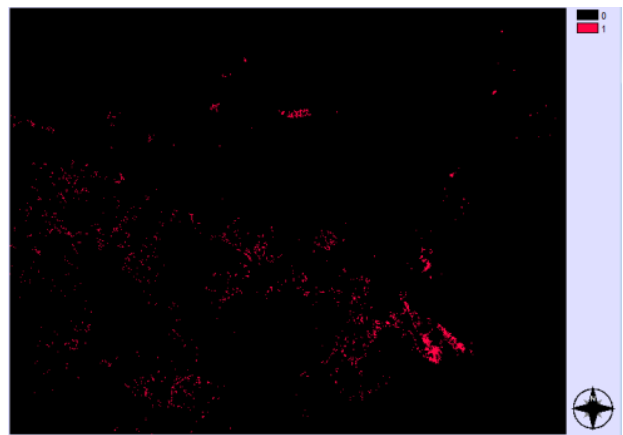

Figure 12 .Map of the probability of reducing agricultural land for the future from comparison of prediction map for 2020 with the actual map for 2014

\section{REFERENCES}

Aarthi, A. D., Gnanappazham, L., 2018. Urban growth prediction using neural network coupled agents-based Cellular Automata model for Sriperumbudur Taluk, Tamil Nadu, India. The Egyptian Journal of Remote Sensing and Space Science, 21(3), 353-362.

https://doi.org/https://doi.org/10.1016/j.ejrs.2017.12.004

Almeida, C. M., Gleriani, J. M., Castejon, E. F., Soares-Filho, B. S., 2008. Using neural networks and cellular automata for modelling intra-urban land-use dynamics. International Journal of Geographical Information Science, 22(9), 943-963. https://doi.org/10.1080/13658810701731168

Bahari, R.A., Abbaspour, R.A., Pahlavani, P., 2014, November. Prediction of PM2.5 concentrations using temperature inversion effects based on an artificial neural network. In The ISPRS international conference of Geospatial information research (Vol. 15, p. 17)

Batty, M., Xie, Y., 1994. From Cells to Cities. Environment and Planning B: Planning and Design, 21(7), S31-S48. https://doi.org/10.1068/b21S031.

Bigdeli, B., Samadzadegan, F., Reinartz, P., 2013. Classifier fusion of hyperspectral and lidar remote sensing data for improvement of land cover classifcation. International Archives of the Photogrammetry, Remote Sensing and Spatial Information Sciences, 1, p.W3.

Bigdeli, B., Samadzadegan, F., Reinartz, P., 2014. Feature grouping-based multiple fuzzy classifier system for fusion of hyperspectral and LIDAR data. Journal of Applied Remote Sensing, 8(1), p.083509.

Dadhich, P. N., Hanaoka, S. (2010). Markov Method Integration with Multi-layer Perceptron Classifier for Simulation of Urban Growth of Jaipur City, 118-123.

Delavar, M.R., Samadzadegan, F., Pahlavani, P., 2004. A GISAssisted optimal urban route finding approach based on genetic algorithms. International archives of photogrammetry remote sensing and spatial information sciences, 35(Part 2), pp.305-308.

Fan, F., Wang, Y., Wang, Z., 2008. Temporal and spatial change 
detecting ( $1998-2003$ ) and predicting of land use and land cover in Core corridor of Pearl River Delta ( China ) by using TM and ETM + images, 127-147. https://doi.org/10.1007/s10661$007-9734-y$

Huang, J., Wu, Y., Gao, T., Zhan, Y., Cui, W., 2015. An Integrated Approach based on Markov Chain and Cellular Automata to Simulation of Urban Land Use Changes, 775(2), 769-775.

Islam, K., Rahman, M. F., Jashimuddin, M., 2018. Modeling land use change using Cellular Automata and Artificial Neural Network: The case of Chunati Wildlife Sanctuary, Bangladesh. $\begin{array}{lll}\text { Ecological Indicators, 439-453. } & \text { 88, }\end{array}$ https://doi.org/https://doi.org/10.1016/j.ecolind.2018.01.047

Jokar, J., Helbich, M., Noronha, E. De., 2013. Spatiotemporal simulation of urban growth patterns using agent-based modeling: The case of Tehran. Cities, 32, 33-42. https://doi.org/10.1016/j.cities.2013.01.005

Kamusoko, C., Aniya, M., Adi, B., Manjoro, M., 2009. Rural sustainability under threat in Zimbabwe - Simulation of future land use / cover changes in the Bindura district based on the Markov-cellular automata model. Applied Geography, 29(3), 435-447. https://doi.org/10.1016/j.apgeog.2008.10.002

Li, H., Reynolds, J. F., 1997. Modeling effects of spatial pattern, drought, and grazing on rates of rangeland degradation: A combined Markov and cellular automaton approach. Scale in Remote Sensing and GIS. New York: Lewis Publishers.

Li, X., Yeh, A. G., 2010. Modelling sustainable urban development by the integration of constrained cellular automata and GIS, 8816. https://doi.org/10.1080/136588100240886

Lin, H., Lu, K. S., Espey, M., Allen, J., 2005. Modeling Urban Sprawl and Land Use Change in a Coastal Area-- A Neural Network Approach, (378-2016-21546), 20. Retrieved from http://ageconsearch.umn.edu/record/19364

Mathur, S., 2019. Impact of an urban growth boundary across the entire house price spectrum: The two-stage quantile spatial regression approach. Land Use Policy, 80, 88-94. https://doi.org/https://doi.org/10.1016/j.landusepol.2018.09.011

Muller, M. R., Middleton, J., 1994. A Markov model of land-use change dynamics in the Niagara Region, Ontario, Canada. $\begin{array}{lll}\text { Landscape } & \text { Ecology, } & \text { 9(2), }\end{array}$ https://doi.org/10.1007/BF00124382

Pahlavani, P., Samadzadegan, F., Delavar, M.R., 2006, September. A GIS-based approach for urban multi-criteria quasi optimized route guidance by considering unspecified site satisfaction. In International Conference on Geographic Information Science (pp. 287-303). Springer, Berlin, Heidelberg.

Pahlavani, P., Sheikhian, H., Bigdeli, B., 2017. Assessment of an air pollution monitoring network to generate urban air pollution maps using Shannon information index, fuzzy overlay, and Dempster-Shafer theory, A case study: Tehran, Iran. Atmospheric environment, 167, 254-269.

Pijanowski, B. C., Brown, D. G., Shellito, B. A., Manik, G. A. (2002). Using neural networks and GIS to forecast land use changes: a Land Transformation Model. Computers, Environment and Urban Systems, 26(6), 553-575.
https://doi.org/https://doi.org/10.1016/S0198-9715(01)00015-1 Rudel, T. K., Coomes, O. T., Moran, E., Achard, F., Angelsen,

A., Xu, J., Lambin, E., 2005. Forest transitions : towards a global understanding of land use change, 15, 23-31. https://doi.org/10.1016/j.gloenvcha.2004.11.001

Saitta, L., 1995. Support-Vector Networks, 297, 273-297.

Tripathy, P., Kumar, A., 2019. Monitoring and modelling spatiotemporal urban growth of Delhi using Cellular Automata and geoinformatics. Cities, 90, 52-63. https://doi.org/https://doi.org/10.1016/j.cities.2019.01.021

Xia, C., Zhang, A., Wang, H., Yeh, A. G. O., 2019. Predicting the expansion of urban boundary using space syntax and multivariate regression model. Habitat International, 86, 126134.

https://doi.org/https://doi.org/10.1016/j.habitatint.2019.03.001

Xiao, J., Shen, Y., Ge, J., Tateishi, R., Tang, C., Liang, Y., Huang, Z., 2006. Evaluating urban expansion and land use change in Shijiazhuang, China, by using GIS and remote sensing. Landscape and Urban Planning, 75(1-2), 69-80. https://doi.org/10.1016/J.LANDURBPLAN.2004.12.005 